DOCUMENTO

\title{
DEMOCRATIZACIÓN DE LA INFORMACIÓN, UNA UTOPÍA URGENTE. Avances de la Propuesta de Investigación Formativa y Aplicada del Programa de Comunicación Social
}

\author{
Por: Carlos Umberto Ospina \\ Milton Cabrera Fernández \\ Sara Marcela Bozzi
}

\section{RESUMEN}

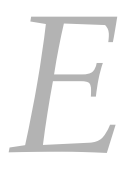

I tema de la democratización de la información es el problema que trata de desentrañar en sus ejercicios de investigación el colectivo de profesores y los estudiantes de los primeros semestres del naciente programa de Comunicación Social, adscrito a la Facultad de Ciencias Sociales y Educación de la Universidad de Cartagena.

\section{Repensar las Estructuras de Comunicación e Información}

A pesar de lo infructuoso que han resultado los esfuerzos emprendidos desde diversos escenarios de la política, el derecho, las ciencias sociales y la literatura, entre otras muchas disciplinas, por generar las bases para un Estado ideal comprometido en el desarrollo de la democracia, en el que se respeten las características individuales hacia la construcción de consensos; una advertencia ha quedado más que clara para todos, para los abanderados de los movimientos políticos de centro, derecha e izquierda, para los defensores de los postulados más liberales o para los conservadores a ultranza, para los idealistas o para los partidarios más radicales del poder dogmático: es un llamado a repensar las estructuras de comunicación y de información en la agenda común de los Estados, en un panorama que abarca desde realidades muy particulares y locales, hasta estructuras globales. Se trata de una misión difícil, toda vez que ambos elementos -comunicación e información- se han convertido, precisamente, en instrumentos de dominio de los ricos y poderosos sobre los pobres y oprimidos. ${ }^{1}$

1 GARCÍA Márquez, Gabriel. La Comisión de Babel, Periódico "El Espectador", 2 de noviembre de 1980

Los esfuerzos emprendidos a lo largo de la historia reciente demuestran que más allá de la retórica soñadora y del anhelo de la armonía política, la democracia y el bienestar general, debe sobrevenir un trabajo arduo y paciente que ha de partir 
de un principio casi utópico: la democratización de la información y de la agenda comunicativa.

Hoy parece imposible pensar en un proceso de democratización global, máxime cuando la globalización está marcada por los intereses particulares de unos pocos que controlan de manera excluyente todos los poderes de lo público, entre ellos los medios de comunicación.

Es claro que en los procesos de democratización, idealistas o utópicos, irreales o soñadores, las agendas deben preocuparse por evitar que se de lo que García Márquez denomina el drama de la comunicación sin regreso y la información pervertida. Para tal fin, será necesario un ejercicio persistente de empatía reflexiva, en el que los postulados del otro sean tenidos en cuenta, sin que ello signifique una adhesión inmediata a sus hipótesis, tal como lo señala Guillermo Hoyos Vásquez en su ensayo "La filosofía política de Jürgen Habermas" cuando sostiene que comprender otras culturas no nos obliga a identificarnos con ellas.

Las realidades son diferentes para unos y otros, muy a pesar de que en el devenir histórico haya problemas comunes que se entrecrucen en ambos extremos. Pero, es esa realidad diferente la que obliga a tener en cuenta al otro para la construcción de auténtica democracia. Es una relación que obviamente se orienta hacia el convencimiento a quien ostenta el poder de su deber de reconocer al débil, con sus características y, sobre todo, a contextualizar el origen de las mismas y a entender sus pretensiones; y, en la dirección contraria, llama al débil a hacer conciencia sobre la importancia de su rol como agente activo en el proceso -no pasivo, como ha sido siempre.

Bien lo precisa Habermas cuando hace referencia a las estructuras comunicativas de la política deliberativa y expone que cuando se reconoce a los otros y se respetan sus máximos se pueden dilucidar aquellos mínimos en los que deberíamos coincidir para vivir pacíficamente.

Es el mismo espacio de lo que llaman la ética cívica mínima, en la que los derechos de una persona llegan hasta donde se inician los de los demás. El simple respeto por las señales de tránsito es una primigenia noción de respeto al otro, medida por un principio mínimo de autoridad. Si bien es cierto que no hay forma posible de lenguaje que democratice tanto la comunicación como las señales universales de tránsito, no es menos verdadero que en el intento por buscar las fórmulas para esa quimera es mucho lo que se puede avanzar. 
Este discurso guarda la misma estructura semántica y, por tanto, se orienta con igual sentido para los niveles global y ciudadano, de manera que debería resultar igualmente interesante para gobernantes, estadistas, activistas y analistas internacionales, entre ellos los periodistas; como para empleadores, trabajadores, dirigentes cívicos y de movimientos obreros y, en últimas, para ciudadanos del común de cualquier provincia latinoamericana, por ejemplo. Y, no por casualidad, de este otro

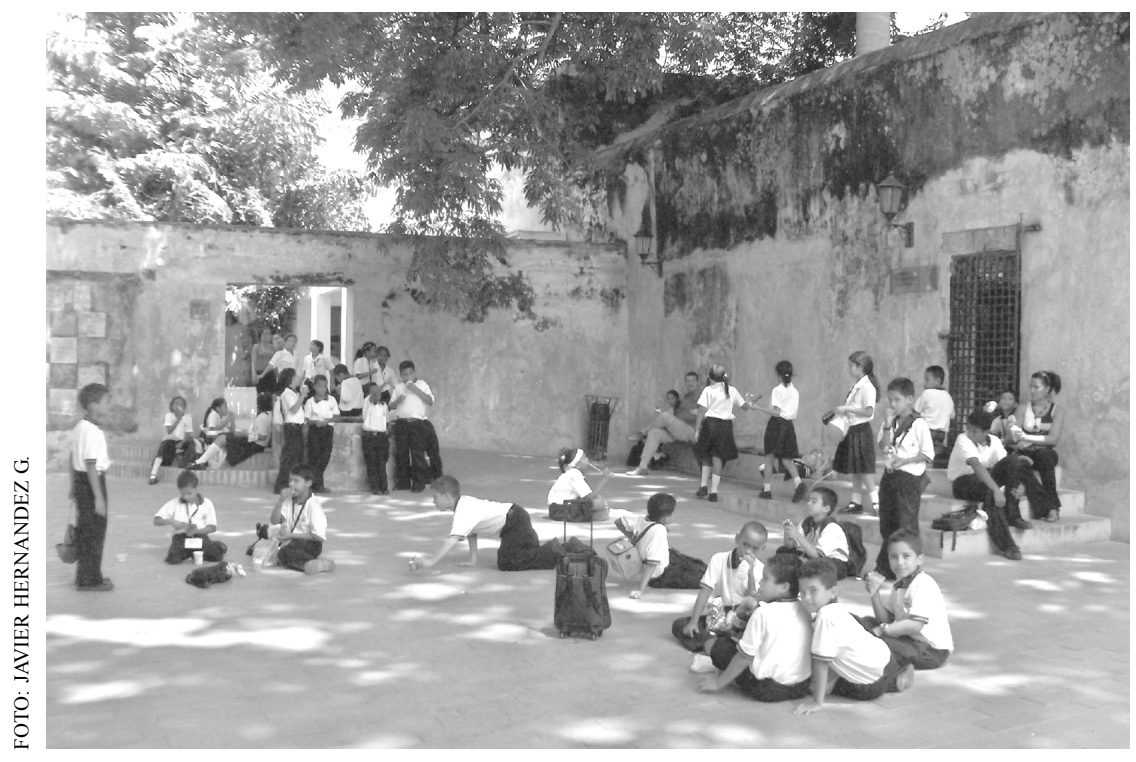
lado también cabrían los comunicadores.

Las agendas comunicativa e informativa, regidas por los predominios de los discursos mediáticos, históricamente $-\mathrm{y}$ hoy más que nunca-, han dejado y dejan muy poco o casi ningún espacio de acción a los débiles y a los pobres. Allí los poderosos tienen todo a su favor para estructurar las agendas de la vida de los demás y hacer del status quo un estilo de vida que se perpetúa y mantiene a unos y otros en el mismo lugar.

Con los medios en el bolsillo, manteniéndolos sin capacidad de reacción, dada su escasa independencia frente a los estados poderosos, los postulados de los últimos prevalecen fácilmente. Sobre este particular el polémico sociólogo francés Pierre Bourdieu, pone de manifiesto su llamado urgente a la democratización de las agendas informativas en Europa, ejemplificando la hipótesis de la ventaja del poderoso sobre el desvalido al anotar que, fruto de un proceso en el que los medios han sido protagonistas, "el neoliberalismo se ha metido de tal manera en la mente de los individuos, que pensar de manera lógica y normal se ha vuelto hoy una paradoja (...) Vivimos una revolución conservadora que quiere restaurar el capitalismo original y salvaje con un nuevo atuendo", una revolución en la que, sin duda, la participación de los medios de comunicación ha jugado un papel preponderante y decisivo.

Insiste Bourdieu en esa tesis al expresar que la ideología de Tietmeyer, Presidente del Deutsche Bundesbank y propulsor del neoliberalismo en Europa, se ha anclado en la mentalidad de la gente, incluso en la de los periodistas, tanto de derecha 
como de izquierda.

Este llamado urgente a la democratización de las agendas de la comunicación y la información no es tema nuevo y, más aun, no ha cambiado a pesar de las transformaciones que en las últimas tres décadas han devenido en la geopolítica mundial. Ya lo advertía García Márquez poco después de intervenir en 1980 en la Comisión McBride, creada para analizar lo que sucedía en la comunicación y en la información en el mundo contemporáneo: “... la democracia es urgente en todas partes, pero no será igual en ninguna, tal como lo sentíamos de 16 maneras distintas en aquellas jornadas quiméricas de nuestra mesa de Babel”, afirmaría quien dos años después se haría merecedor al Premio Nóbel de Literatura.

Pero, la pregunta base y que se convierte en el punto de toque de este análisis es ¿cómo hacer para que esos propósitos de democratización de dos procesos tan amplios y complejos, como lo son comunicación e información, se hagan realidad en medio de tantos intereses empresariales, políticos y estatales?

La invitación es a reflexionar y a hacer reflexionar y, en ese sentido, la academia juega un papel fundamental, dado la orientación de su deber ser hacia la formación de hombres y mujeres con criterio, capacidad y conocimientos del entorno, suficientes para afrontar la discusión de estos temas con clara conciencia del papel frente a la sociedad globalizada de hoy, para que las nuevas generaciones puedan asumir con entereza el rol de transformadores y agentes de cambio. Abordar el tema, generar espacios de permanente reflexión sobre nuestro quehacer disciplinar y auspiciar inquietud desde la base misma de la formación del comunicador sobre la responsabilidad social de su oficio, nos permitirá, al menos, disminuir aunque sea en el plano del imaginario académico y gremial, el silencio cómplice que hay en el mundo actual alrededor de este proceso de oligopolización de las agendas informativa y comunicativa del mapa contemporáneo.

\section{¿Cómo lo Estamos Haciendo?}

Entendiendo como un compromiso la necesidad de generar un ejercicio reflexivo permanente en torno a este gran tema, el Programa de Comunicación Social de la Universidad de Cartagena ha puesto en marcha un nuevo proceso educativo, cuyo propósito es acercar las lógicas de las ciencias y sus correspondientes formas de investigar a la lógica del proceso enseñanza-aprendizaje. Para tal fin, un esquema de investigación desde el inicio mismo del periplo educativo del 
Programa, el cual contempla el trabajo con base en Ejes Temáticos y su desarrollo investigativo a partir de un Núcleo Problémico, que deberá ser "resuelto" durante cada semestre.

Tanto para los estudiantes de primer semestre, como para los de segundo, el Eje Temático es "Comunicación y Cultura". Ahora bien, el Núcleo Problémico para Primer Semestre corresponde a la pregunta ¿Cómo democratizar la información en un mundo globalizado?, la cual deberá ser desglosada o sistematizada en subpreguntas que de su esencia se desprendan, mientras que para los equipos de investigación de segundo semestre, se han sugerido las siguientes subpreguntas, que surgieron de las expectativas y necesidades planteadas por los estudiantes y el equipo académico del Programa:

1. ¿Cómo se muestran en los medios de comunicación las "voces" y "rostros" de los sectores más débiles de la sociedad?

2. ¿Cuáles son las fuentes utilizadas por los medios de comunicación para trabajar sobre el tema de la globalización?

3. ¿Cuáles son las principales limitaciones o presiones que tienen los medios informativos con relación a la superación de la situación de pobreza a nivel regional y nacional?

4. ¿Hasta qué punto, en el país, los medios de comunicación determinan las agendas públicas que podrían contribuir a superar la desigualdad?

5. ¿Cuál es la propuesta de agenda ciudadana que circula en los medios de comunicación?

6. ¿Cómo son tratados en los medios de comunicación los temas sociales en general y la desigualdad y la pobreza en particular?

Los estudiantes de segundo semestre podrán plantear inquietudes diferentes a las sugeridas o continuar con su ejercicio de investigación del período anterior.

En virtud de que se ha concebido el proceso como un esquema interdisciplinario, en el que cada campo del saber (Teorías de la Comunicación, Sociología, Fundamentos del Derecho, Diseño de la Investigación, Teoría del Conocimiento, Filosofía, Economía, Expresión Oral, Expresión Escrita) debe enriquecer el trabajo de los estudiantes haciendo los respectivos aportes desde sus contenidos, se considera oportuno y pertinente que todos los docentes manejen con claridad el esquema que se inicia, a fin de propiciar un ejercicio de reflexión, análisis e investigación consecuente con las cada vez más crecientes exigencias pedagógicas y, sobre todo, con las exigencias sociales y culturales del mundo de hoy. 
Esta experiencia desde el aula ha arrojado excelentes resultados. Sólo en el primer semestre, cuarenta estudiantes tuvieron una aproximación al rigor investigativo al analizar temas como la influencia del estatus socio-económico de las naciones poderosas en el tratamiento de la información cultural en la televisión colombiana, el impacto de la democratización de la información en un mundo que camina hacia un único poder político, económico, social y cultural, por qué la educación es un factor sociocultural que exige la democratización de la información en un mundo globalizado.

En el semestre actual (julio-diciembre de 2004), 78 estudiantes de primero y segundo semestre trabajan en el análisis de temas como las tensiones, presiones, censuras y autocensuras de los medios de comunicación, el manejo de las fuentes informativas y su relación con la democracia, la influencia de los medios en la definición de las agendas públicas y ciudadanas, la necesidad de visibilizar en los medios a los sectores más vulnerables de la sociedad, las normas constitucionales y legales que sustentan la democratización de la información, los factores institucionales que obstaculizan los procesos de democratización de la información en la Escuela "Sueños y Oportunidades" de la comunidad de Nelson Mandela, en Cartagena, y el uso de los conocimientos tradicionales locales para la democratización de la información, entre otros.

\section{Semilleros de Investigadores}

Con tan sólo un año de haber iniciado labores académicas, los estudiantes de Comunicación Social de la Universidad de Cartagena hacen parte de dos semilleros de investigación. El primero en la Facultad de Ciencias Sociales y Educación, en el cual apoyarán investigaciones relacionadas con la Pedagogía Social, a través del estudio de la radio cartagenera como constructora de imaginarios de ciudad y del impacto de los medios en el refuerzo de los imaginarios culturales de poder a través de los cuales los colombianos ejercemos violencias simbólicas en nuestras interrelaciones.

Estas dos temáticas responden a igual número de investigaciones que se han venido adelantando en la Facultad de Ciencias Sociales. El estudio de la radio comercial cartagenera entendida como un espacio público a través del cual es posible potenciar a Cartagena como ciudad educadora, es una propuesta que viene adelantando la investigadora Carmen Cabrales, en desarrollo del mismo, se adelantó en el año 2003 un trabajo desde la especialización en Teoría, Métodos 
y Técnicas de Investigación Social, que buscaba encontrar relaciones entre la agenda ciudadana propuesta por la radio y los principios de la propuesta de ciudad educadora; este estudio se adelantó mediante un análisis de contenido de una amplia muestra de programas radiales, identificando los mensajes emitidos para diversas categorías, tales como salud pública, seguridad, agua, identidad y pertenencia, democracia, etc.

El otro estudio, sobre las relaciones entre los niños y niñas de escuelas de la zona de influencia de Mamonal con los medios de comunicación, hizo parte de la investigación sobre "El Conflicto como Oportunidad Educadora" realizada entre el 2003 y 2004. El componente de comunicación indagó sobre el consumo de medios por parte de los menores, y adelantó también un ejercicio de análisis de contenido de los dos programas televisivos más vistos por ellos, en busca de encontrar las mencionadas relaciones entre los mensajes del Chavo del Ocho y Pockemón, con los imaginarios culturales de poder que incitan a ejercer violencias simbólicas y fácticas e impiden asumir el conflicto como oportunidad educadora.

El otro semillero en el cual participan nuestros estudiantes se ubica en la Facultad de Ciencias Humanas, dando vida al carácter interdisciplinar y asociativo con el que se diseñó el Programa, en donde abordan la línea de los análisis de discurso y contenido, y en el que han iniciado un trabajo sobre la discriminación racial desde los medios locales de comunicación. Este grupo de profesores y estudiantes del Programa de Comunicación Social se ha unido al semillero de investigación "TEXCULTURA" que vienen liderando en el programa de Lingüística y Literatura los profesores Clara Inés Mendoza, Freddy Ávila Domínguez, Juan Carlos Durango y Osiris Chajín Mendoza. Se trata de continuar con un plan de acompañamiento y entrenamiento de la actividad investigativa, en general, y en la del "análisis del discurso" en particular, que beneficie a estudiantes y docentes para interpretar los contenidos de la prensa local y rastrear las formas de exclusión "de los otros" en las páginas de los diarios regionales. Se buscará hacer una recopilación de una serie de datos orales y escritos acerca de "discursos sobre los otros" en Cartagena.

El principal aporte del grupo de comunicadores a "Texcultura" es el de proveer las estrategias del análisis cualitativo de contenido, para desentrañar las "trampas" del lenguaje a través de las cuales se discrimina al negro, al joven, al anciano, a las mujeres, al indígena, al "cachaco" y a todos los grupos vulnerables de la sociedad. El análisis cualitativo de contenido que se viene trabajando desde el programa de Comunicación Social conduce a una descripción fundamentada 
del contenido manifiesto. Sin embargo, siguiendo las recomendaciones de Freud en su tratado "Interpretación de los Sueños", busca la formulación de inferencias acerca del emisor y de los receptores, así como del contenido o significado latente del mensaje, lo que nos introduce ya en el terreno de lo cultural. El verdadero análisis de contenido siempre debe tratar de sacar a la luz aquellas relaciones ocultas que pasan desapercibidas para los lectores que leen rápidamente un texto sin incursionar en la lectura ideológica, aquella que descubre la intencionalidad de un escritor.

\section{Otros Escenarios de Investigación}

El Programa de Comunicación Social de la Universidad de Cartagena nació con la importante fortaleza institucional relacionada con la trayectoria de cuatro lustros de trabajo en iniciativas de producción, desarrollo e investigación en el campo de los medios de comunicación.

La política de Comunicación Social impulsada ininterrumpidamente durante los últimos veinte años en la Universidad de Cartagena ha sido abordada en su aspecto espacial atendiendo el contexto local y regional del Caribe colombiano, el contexto nacional, el contexto latinoamericano y el contexto global.

En reciente visita a la Universidad de Cartagena, el profesor José Miguel Pereira expresó muy bien esta posición de nuestra Alma Máter al hablar de los desafíos que plantea la relación comunicación / educación, a partir de una reflexión en torno a la guerra y los hilos entrecruzados que en su tejido creado de nudos de desigualdad, inequidad, e injusticia, hijas todas ellas de la corrupción, el clientelismo, el negocio de las drogas ilícitas, la exclusión política, económica y social y la ceguera de una clase dirigente incapaz de comprender la necesidad de ceder parte de sus privilegios en aras de un mejor futuro para todos los colombianos, incluyendo a sus propios descendientes. Los procesos de comunicación, tanto desde el ejercicio periodístico y mediático como en la comprensión y generación de mediaciones, son ejes fundamentales en este espinoso camino que debe transitar Colombia para salvar una posición digna en el contexto planetario del tercer milenio de la era cristiana:

"La construcción de una sociedad más democrática se relaciona, en primer lugar, con la construcción de lo público entendido como los espacios simbólicos de los que todos los ciudadanos se pueden comunicar y son interlocutores de todas las voces y proyectos de los diversos grupos y organizaciones que conforman la sociedad. Espacios en los que tiene que caber la palabra y la imagen en sus múltiples 
${ }^{2}$ PEREIRA, José Miguel. Comunicación $\quad \mathrm{y}$ Educación: Desafíos para el Caribe Colombiano. Texto presentado en el seminario sobre Comunicación para el Desarrollo, Universidad de Cartagena, septiembre 2002. Pág. 2

${ }^{3}$ Ibid. Pág.7 manifestaciones, tales como el debate, la fiesta, la expresión de la memoria. Por eso, hablar de comunicación para construir lo público, implica ante todo abrir espacios para la deliberación, la participación, la reflexión, la controversia, el conflicto, la expresión y la palabra entre los ciudadanos" ${ }^{2}$

Desde nuestra percepción, el ejercicio universitario de la Comunicación Social tiene entonces su principal razón de ser en la dimensión estratégica para pensar la sociedad, que como tal exige y obliga a preguntarse por cada uno de los niveles del contexto, para dar respuestas generadoras de cambio en las relaciones entre lo local, lo regional, lo nacional, lo continental, y lo global.

Creemos que la adecuada percepción y relación con la nación y con el mundo se facilitará desde una clara comprensión de la región, sin por ello quedarse en el plano de lo provinciano, tal como se registra en la famosa sentencia de Tolstoi: "describe tu aldea y serás universal". En este sentido, el accionar de los medios de comunicación universitarios tiene que ofrecer escenarios concretos a la población, donde la región no resulte de un accidente geográfico, sino de una construcción del sentido de un nuevo concepto de ciudadanía, que ha de ser de dimensión planetaria. La comunicación pensada en estos términos tiene el doble reto de ser vehículo (medio) para la construcción de la región y del país y al mismo tiempo, resultado de la comprensión y ubicación que hagamos de ella dentro del contexto mundial.

Existen sustanciales diferencias entre la región del Caribe colombiano con el resto de la nación, dada su cultura, sus percepciones, representaciones y valores. El concepto de la diferencia se concreta aquí en un compromiso frente a la investigación en comunicación y los aportes que se puedan ofrecer desde la práctica comunicativa de los medios masivos, para la reflexión y discusión política en torno a las relaciones centro-periferia, y entre las distintas regiones que conforman el país, con miras a afianzar el imaginario de unidad nacional en una sociedad donde "verdaderamente quepan todos, su pluralidad regional, cultural, étnica y los distintos modos de pensar que han sido silenciados y excluidos del debate público y de la esfera pública en su conjunto”3 ${ }^{3}$.

Según el investigador Omar Rincón, "el criterio de lo nacional cada vez convoca menos; nuestros mitos fundadores como nación se derrumban; cultural y políticamente estamos cada día más lejos de sentirnos parte de una nación, un pueblo, una identidad. Desde la Comunicación tenemos que preguntarnos por los mitos fundadores de lo nacional, las posibilidades de encontrar nuevas formas de juntarnos como nación, el sentido de la representación en un mundo cada 
vez más globalizado, el papel de las mediaciones comunicativas dentro de los conceptos de colombianidad e identidad" 4

Entonces, el impulso de una política de comunicación tan definida como la de la Universidad de Cartagena, con sus recientes proyectos -un nuevo Programa de Comunicación Social, una estación de televisión educativa, una emisora de interés público y sus publicaciones periódicas y especializadas- ha de tener clara participación en torno a los desafíos para la comunicación y la educación en la Colombia del siglo XXI, que incluyen la necesidad y el compromiso de pensar nacionalmente, para contribuir aún desde una lectura de lo local y lo regional a una lectura de lo nacional e internacional reflexionando sobre la crisis estructural que vive Colombia. Aspectos como el pluralismo y la inclusión, son desafíos del orden nacional que justifican un impulso a la comunicación social con medios

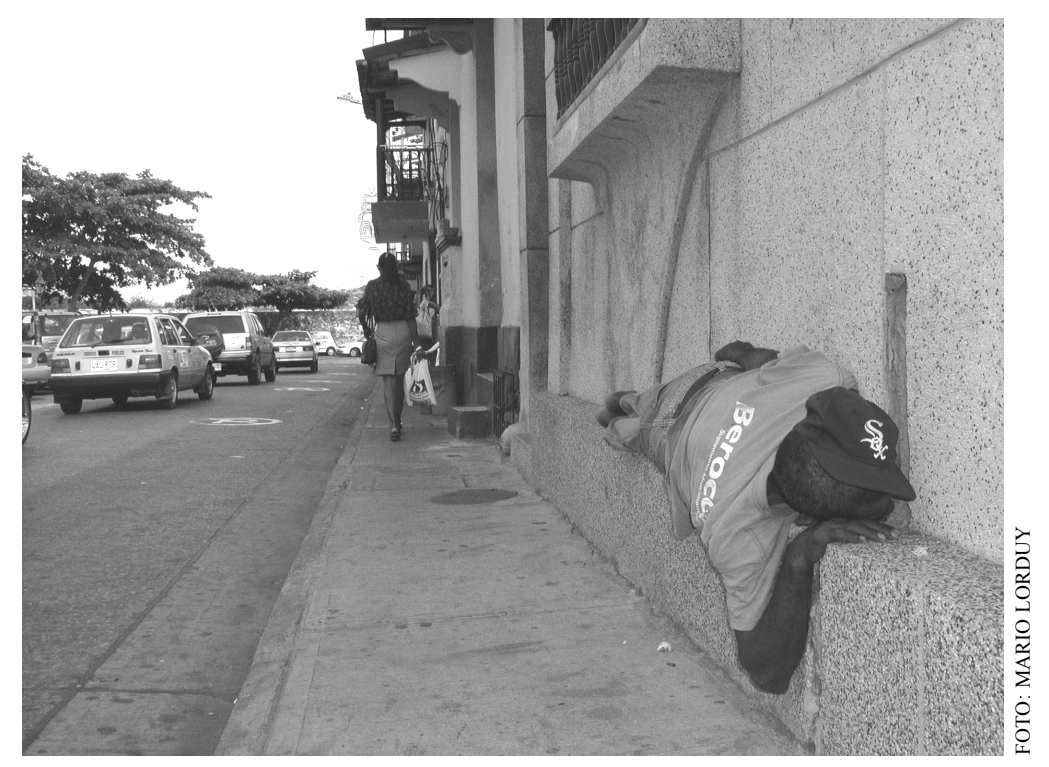
masivos, que coadyuve a la construcción de un verdadero sentido de ciudadanía a través del cual los colombianos se interesen y actúen frente a los asuntos públicos y ocupen los espacios que creó la constitución política de 1991.

Tales espacios para pensar, investigar y hacer la comunicación involucran también el contexto local. Por lo tanto, esta política institucional de Comunicación de la cual hacen parte los proyectos de las estaciones televisiva y radial, se justifica igualmente por su aporte potencial a la agenda de investigación en comunicación en torno a la cultura urbana y las nuevas identidades que implican modos de tejer sociedad; la cultura tecnológica, el mundo audiovisual y las sensibilidades de los jóvenes; los medios y la conformación del sentido y el conflicto; los cambios en los modos de representación política; los nuevos actores sociales; y los retos de la comunicación a la educación.

Innegablemente, esta agenda responde fundamentalmente a los cambios generados por las revoluciones tecnológicas y de las comunicaciones vividas en los últimos cien años y particularmente en los últimos veinte, con el advenimiento de la red mundial, los cuales nos harán cada vez más ciudadanos del mundo: "Todo ciudadano asiste y actúa en medio de una economía y tecnología

${ }^{4}$ RINCON, Omar. La Comunicación está de Moda (... en busca de la comunicación para los comunicadores). En: Revista Unicarta 98, Universidad de Cartagena, abril de 2003. Pág. 13 
globalizada y una cultura y política mundializada" ${ }^{5}$

Finalmente, es importante resaltar la vocación nacional que en materia de Comunicación Social ha tenido la Universidad de Cartagena, para generar proyectos cuyo impacto trascienda las barreras de lo local y lo regional al nacional e internacional. En este sentido, el Programa de Comunicación Social, el canal televisivo y la emisora radial se constituyen en magníficas oportunidades y fortalezas para afianzar dicha vocación, a través de un trabajo en redes de cooperación que involucran diversos agentes de desarrollo gubernamental y no gubernamental.

\section{Por una Emisora de Interés Público}

Por delegación de la Rectoría, la Facultad de Ciencias Sociales y Educación se ha involucrado desde el Programa de Comunicación Social en una investigación que sustente la iniciativa del Centro de Recursos Educativos de poner en funcionamiento una emisora de interés público en la Universidad. Dicha investigación incluye el diseño completo del proyecto comunicativo, estado de arte, marco conceptual y los estudios de factibilidad, viabilidad y sostenibilidad cultural, a partir de un proceso de consulta ciudadana que se encuentra en plena ejecución.

El objetivo general de este proyecto de Investigación y Desarrollo, es obviamente crear una Emisora de Interés Público en la Universidad de Cartagena, económica y socialmente viable, fundada en los principios de construcción de ciudadanía democrática cultural al servicio de procesos de educación y pedagogía social para el mejoramiento de la calidad de vida de la población de su área de influencia en los ámbitos formal, no formal e informal, con el propósito de contribuir desde la Universidad Pública a la plena inserción de la sociedad colombiana en concierto globalizado de la era de la información y el conocimiento.

\section{Producción Televisiva para la Educación, la Ciencia y la Cultura}

${ }^{5}$ ORTIZ, Renato, Otros Territorios, Bogotá: SECAB, 1998. REY, Germán, Balsas y Medusas, Bogotá, Fescol - Cerec, 1999. GARCÍACANCLINI, Néstor. Consumidores $\quad \mathrm{y}$ Ciudadanos, México, Grijalbo, 1995
Así mismo, y a pesar de estar suspendida la producción televisiva del proyecto ORIGENES, una experiencia de investigación-acción centrada en la búsqueda de nuevos lenguajes de televisión educativa, científica y cultural; actualmente se adelanta una iniciativa que asegura la continuidad de este importante proyecto de comunicación emanado de nuestra Alma Máter, que incluye además un componente de producción televisiva. 
Se trata de la propuesta del Festival Ver Ciencia Caribe, derivada del compromiso adquirido por la Universidad en 1998, durante el Simposio "Europa-América Latina: imágenes y ciencia hacia el tercer milenio", al cual fue invitado el director del Programa ORIGENES. De dicho compromiso, relacionado con la organización de una iniciativa denominada Ver Ciencia Internacional, surgió el actual proyecto de investigación que ha propuesto nuestra Universidad, desde el Programa de Comunicación Social, al instituto rector del fomento a la investigación científica y tecnológica en el país -COLCIENCIAS-, que luego de estudiarlo, ha aprobado su cofinanciación.

\section{Comunicación Social: Un Proyecto Académico de Pregrado Centrado en la Investigación Formativa y Aplicada}

El Programa de Comunicación Social de la Universidad de Cartagena, ha puesto en escena durante el segundo período del año 2004, dos eventos estrechamente ligados a los énfasis que ofrece la carrera, con el fin de abrir opciones a nuestros estudiantes para que se proyecten hacia el futuro divisando las inmensas posibilidades de desempeño del comunicador social: como escritores, como guionistas, realizadores, directores y generadores de todo tipo de producción educativa formal y no formal, a través de las cual pueden jalonar procesos de cambio social de una manera creativa. En el primer evento -Televisión y Universidad: Un Encuentro Necesario, se hizo una aproximación a las formas cómo el comunicador puede apropiarse del mundo de las imágenes para contar historias con un propósito educativo.

Entre las propuestas más novedosas, estuvo la iniciativa de buscar un modo activo de ver telenovelas, género popularizado en América Latina y España, para partir del nivel de conciencia de los espectadores y conducirlos a reflexionar sobre su vida cotidiana.

En su libro, "Melodrama y Televisión" ${ }^{6}$ Jesús Martín Barbero y la investigadora de la Universidad del Valle, Sonia Muñoz, plantean la importancia de estudiar cómo los distintos sectores sociales, en su vida diaria, se apropian de manera diferencial de los contenidos de las telenovelas. Pero es indudable que todos los incorporan a su vocabulario en el trabajo, en la familia, en la buseta, en sus ratos de ocio, salpicados por esa capacidad narrativa de los iberoamericanos que los conduce a anticipar lo que ocurrirá mañana.

6 MARTÍN Barbero, Jesús. MUÑOZ, Sonia y otros. Melodrama y Televisión. Tercer Mundo Editores, Bogotá, 1992.

¿Cómo estudiar este fenómeno sin caer en el reduccionismo de la semiótica o en lo

Sin referir página. 
superficial de la encuesta? Martín Barbero plantea que es necesario combinar diferentes técnicas para construir el sentido de las telenovelas, cuyo discurso es atravesado por una clave irónica que la asemeja a la vida diaria del colombiano, quien debe recurrir cada día a una buena dosis de humor para poder soportar la rutina, la falta de movilidad social y la escasez de oportunidades para sobrevivir en paz.

Una de las primeras formas de utilizar la telenovela para fines educativos es ir a los barrios a hablar con la gente sobre los gustos y preferencias de los programas televisivos, preguntando en cada caso, ¿cuáles son los buenos, y cuáles son los malos?, ¿qué hubiera hecho usted en una situación semejante?, ¿qué va a pasar cuando se descubra tal secreto?

Otra técnica interesante ensayada en la Universidad del Valle ha sido la de organizar talleres de discusión con mujeres, ancianos o jóvenes de diversas clases sociales. Se graba un capítulo y se ve con ellos. Cinco minutos antes que termine ese capítulo se detiene la grabación y se pide a la gente que diga cómo debería terminar. Esto sirve además para darse cuenta de la capacidad narrativa de las diferentes personas, para descubrir ese "libretista interno" que hay detrás de cada uno de nosotros.

Es notorio verificar así que la gente se relaciona de manera distinta con el medio, según su edad, sexo, profesión u oficio. Por ello, propone Martín Barbero, es muy importante construir, junto al televidente, su historia de vida, recordando cuáles son las telenovelas que han jugado un papel importante en su vida. Se trata de sostener diálogos profundos con personas representativas de una comunidad para que cuenten, con la voz del corazón, qué les ha dejado la televisión.

Otro de los eventos importantes organizados por el programa de Comunicación Social de la Facultad de Ciencias Sociales y Educación es el seminario internacional de periodismo cultural -Nuevas Voces, Nuevos Rostros- a partir del cual hemos reflexionado sobre el periodismo de opinión como una pausa oxigenante en la era del vértigo.

El futuro del periodismo está en la posibilidad de analizar, interpretar y comunicar una visión del mundo decantada, que no se limite a contar los acontecimientos con la frialdad de una máquina registradora, sino al calor de los latidos del corazón. El ser humano debe dejar su huella, sus emociones y su alma en cada crónica que dibuja en su cerebro para dejar un testimonio de la aventura intelectual de su época. 
En la tarea de concebir el periodismo como un arte, hemos recibido el apoyo de la Fundación para un Nuevo Periodismo Iberoamericano, fundada por Gabriel García Márquez, que se ha propuesto, entre otras cosas, dignificar el oficio. También hemos recibido las lecciones de la Universidad de Servilla, la Universidad Javeriana y la Universidad de La Laguna en España, quienes han estado atentos a la formación integral de nuestros estudiantes.

Nuestra escuela de periodismo pretende recoger las mejores lecciones que nos ha legado el gran maestro del periodismo universal, Gabriel García Márquez. En distintas ocasiones, como en su fantástica autobiografía de 579 páginas, nuestro premio Nóbel nos ha enseñado que lo importante no es buscar una caracterización exhaustiva entre géneros periodísticos y literarios, sino en buscar que nuestros futuros profesionales logren destrezas en el arte de narrar. En el arte de contar historias que sepan conmover al lector, al ciudadano. Su posición es la de conceder a la narración el mismo estatus de la realidad externa y por eso es certero cuando afirma sin pudor: "La vida no es la que uno vivió sino la que uno recuerda para contar".

Por lo tanto, creemos que el periodismo necesita de una nueva pedagogía que permita a sus estudiantes abrazar la profesión con verdadera vocación y con la misma entrega de aquellos grandes periodistas como Alvaro Cepeda Samudio, Guillermo Cano, Alberto Zalamea Borda que dejaron su propia vida, entregada gajo a gajo en cada página que salía con fruición de sus viejas máquinas de escribir.

Para lograr esta actitud hay que luchar contra la rapidez de la noticia y buscar que el periodista se sintonice con la aventura de vivir las preocupaciones espirituales e intelectuales de una época y, sobretodo, vivir en constante diálogo consigo mismo, como parte de una realidad en la que se goza y se sufre, se trabaja y se descansa, se reza, se maldice, se crea el mundo para que no desaparezca para los ciudadanos del futuro que no sólo reciben de herencia unas construcciones y monumentos tangibles, sino también unos mitos, unos miedos, unas creencias que formarán parte de su existencia, demarcándola y haciéndola rica y vigorosa.

El periodismo así entendido será la profesión más fascinante del futuro en la medida en que permitirá a la sociedad verse reflejada en el espejo de sus propias contradicciones, de sus luces y sombras, para enfrentarse al devenir, como bien lo dijera García Márquez, en alguno de sus textos sobre el oficio, "el periodismo 
merece no sólo una nueva gramática, sino también una nueva pedagogía y una nueva ética del oficio y visto como lo que es sin reconocimiento oficial: un género literario mayor de edad, como la poesía, el teatro y tantos otros. A ver si con un reconocimiento tan justo -entre tantos sofismas de distracción- los periodistas colombianos nos le medimos por fin al reportaje inmenso que se espera de nosotros: cómo es que la Colombia idílica de los poetas se nos ha convertido en el país más peligroso del mundo".

\section{BIBLIOGRAFÍA}

MARTÍN Barbero, Jesús. "Pretextos", Colección Ensayo Iberoamericano, Centro Editorial Universidad del Valle. Cali, Colombia, 1995

GARCÍA Márquez, Gabriel. "La Comisión de Babel", El Espectador, 2 de noviembre de 1980.

LENGUAJE Y CULTURA, de la serie Lunes de Debate. Departamento de Filosofía, Universidad del Valle, Cali, Colombia, 2002

MARTÍN Barbero; Jesús; MUÑOz, Sonia y otros. "Melodrama y Televisión", Tercer Mundo Editores, Bogotá, 1992

RINCON, Omar. "La Comunicación está de Moda" (...en busca de la comunicación para los comunicadores). En: Revista Unicarta 98, Universidad de Cartagena, abril de 2003

ORTIZ, Renato. "Otros Territorios", Bogotá: SECAB, 1998

REY, Germán. "Balsas y Medusas", Bogotá, Fescol - Cerec, 1999

GARCÍA-Canclini, Néstor. "Consumidores y ciudadanos", México, Grijalbo, 1995

PEREIRA, José Miguel. "Comunicación y Educación: Desafíos para el Caribe Colombiano". Texto presentado en el seminario sobre comunicación para el desarrollo, Universidad de Cartagena, septiembre 2002

ÁMBITOS, Revista Internacional de Comunicación, Número Especial 9-10, Universidad de Sevilla, Sevilla, España, 2003

FERNÁNDEZ Collado, Carlos. "La Comunicación Humana en el Mundo Contemporáneo", McGraw-Hill, México D.F., México, 2000

CLAUSTRO DE PROFESORES, Programa de Comunicación Social, Facultad de Ciencias Sociales y Educación, Universidad de Cartagena; "Documento de sistematización de las experiencias de aproximación a la investigación de los estudiantes del Programa", agosto de 2004 


\section{BIOGRAFÍA}

\section{SARA MARCELA BOZZI ANDERSON}

Comunicadora Social - Periodista, Doctora en Ciencias de la Información, Directora del Programa de Comunicación Social de la Universidad de Cartagena.

\section{MILTON EDUARDO CABRERA FERNÁNDEZ}

Comunicador Social - Periodista, Especialista en Comunicación Organizacional, Profesor de tiempo completo del Programa de Comunicación Social de la Universidad de Cartagena.

\section{CARLOS UMBERTO OSPINA BOZZI}

Comunicador Social, Experto en Educación a Distancia para el Desarrollo, Especialista en Administración de Programas de Desarrollo Social, Profesor de tiempo completo del Programa de Comunicación Social de la Universidad de Cartagena. 